\title{
Fall Armyworm Invasion and Impact in Africa ${ }^{\dagger}$
}

\section{Jerome Abiemo}

Faculty of Veterinary and Agricultural Science, University of Melbourne, Building 142, Royal Parade, Parkville, Victoria 3052, Australia; jabiemo@student.unimelb.edu.au

+ Presented at the third International Tropical Agriculture Conference (TROPAG 2019), Brisbane, Australia, 11-13 November 2019.

Published: 25 December 2019

\begin{abstract}
Maize is a major staple food crop grown in diverse ecological zones and consumed by many people in Sub-Saharan Africa (SSA). An estimated 208 million people in Africa depend on maize as a food security crop and a major source of calories. Similarly, a vast majority of smallholder farmers cultivate maize for its economic returns. However, in recent years, maize yields from various fields across Africa have declined due to the invasion of Fall Armyworm (FAW) Spodoptera frugiperda. The study presents a literature review on the widespread distribution and impact of FAW on maize yields in Africa. The study identifies that maize yield loss in most countries continues to increase, which poses a present and future food security threat to farmers and their families. While most farmers have adopted various chemicals to control FAW, the majority of these chemicals are associated with health and environmental problems. The study, therefore, recommends extensive education of farmers on the early identification of FAW and appropriate management and control methods. It also stresses the need for various governments, as part of the national policy, to focus on environmentally safe and sustainable control methods to reduce the impact of FAW and increase maize yields.
\end{abstract}

Keywords: Fall Armyworm (FAW); maize yield; food security; control methods

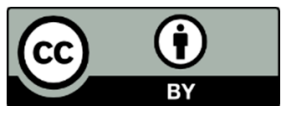

(C) 2019 by the authors. Licensee MDPI, Basel, Switzerland. This article is an open access article distributed under the terms and conditions of the Creative Commons Attribution (CC BY) license (http://creativecommons.org/licenses/by/4.0/). 